\title{
Nonprescription Bleaching versus Home Bleaching with Professional Prescriptions: Which One is Safer? A Comprehensive Review of Color Changes and Their Side Effects on Human Enamel
}

\author{
${ }^{1}$ Conservative Dentistry Unit, School of Dental Sciences, Universiti \\ Sains Malaysia, Kelantan, Malaysia \\ 2Prosthodontic Unit, School of Dental Sciences, Universiti Sains \\ Malaysia, Kelantan, Malaysia \\ ${ }^{3}$ Dental Public Health Unit, School of Dental Sciences, Universiti \\ Sains Malaysia, Kelantan, Malaysia
}

Farhana Omar ${ }^{1}$ Zuryati Ab-Ghani $\quad$ Normastura Abd Rahman ${ }^{3} \quad$ Mohamad Syahrizal Halim

\begin{abstract}
Address for correspondence Mohamad Syahrizal Halim, MRestDent, Conservative Dentistry Unit, School of Dental Sciences, Universiti Sains Malaysia Health Campus, 16150 Kota Bharu, Kelantan, Malaysia (e-mail: drsyah@usm.my).
\end{abstract}

Eur J Dent 2019;13:589-598

\begin{abstract}
Objectives This study evaluates the efficacy and safety of the professionally prescribed and nonprescription over-the-counter (OTC) bleaching agents.

Materials and Methods Extracted human upper central incisors were prepared and stained with red wine for 14 days before being subjected to four different bleaching agents: professionally prescribed opalescence PF $15 \%$, VOCO Perfect Bleach $10 \%$, nonprescription OTC Crest 3D Whitestrips, and Whitelight Teeth Whitening System. Colorimetric measurement was performed with Vita Easyshade Handheld Spectrophotometer, enamel surface microhardness measured using Vickers Hardness machine, and surface roughness was evaluated with profilometer, before and after bleaching. Scanning electron microscope (SEM) evaluation and atomic force microscopy were conducted postbleaching.

Keywords

- bleaching

- home bleaching with professional prescriptions

- nonprescription bleaching

- efficacy of bleaching

- surface roughness of enamel

- microhardness of enamel

Statistical Analysis The data were analyzed with $t$-test, two-way ANOVA, one-way ANOVA, and Turkey's test at a significance level of $5 \%$.

Results All bleaching products have the same efficacy to whiten stained enamel. Opalescence PF 15\% showed significant increase in the microhardness (92.69 \pm 68.316$)$. All groups demonstrated significant increase in surface roughness $(p<0.05)$. SEM evaluation showed that Opalescence PF 15\% resulted in same microscopic appearance as unbleached enamel, while VOCO Perfect Bleach $10 \%$, Whitelight Teeth Whitening System and Crest 3D Whitestrips demonstrated mild to moderate irregularities and accentuated irregularities, respectively.

Conclusion Professionally prescribed bleaching agent of Opalescence PF 15\% is effective tin whitening the teeth, while the other bleaching products may be effective but also have deleterious effects on the enamel.
\end{abstract}

\section{Introduction}

In recent years, with the increasing trend and desire for whiter teeth to enhance aesthetic appearance, tooth bleaching is becoming a popular choice of treatment among patients. ${ }^{1}$ Current tooth bleaching regime ranges from professionally applied in-office bleaching, professionally prescribed (PB) home bleaching, nonprescription over-the-counter (OTC) bleaching to the do-it-yourself (DIY) regime. ${ }^{2-4}$

Bleaching treatment is considered to be the most conservative, safe, effective, and minimally invasive method to 
overcome external and internal tooth discoloration. ${ }^{5}$ Professionally prescribed home bleaching agent has been proven to be efficient to whiten discolored teeth. ${ }^{6}$ Professionally prescribed home bleaching is closely monitored by the dentist, thereby ensuring their safety and increasing the effectiveness of the bleaching procedure ${ }^{2,7}$

The availability and easy access to non-prescription (OTC) bleaching products have increased their popularity. This regime is less time consuming, low cost, and avoids the need for an extra appointment with the dentist as compared with professionally prescribed home bleaching agent. ${ }^{8}$ However, the safety issues of these bleaching agents remain controversial as the U.S. Food and Drug Administration (FDA) does not verify certain products. Unsupervised bleaching with nonprescription OTC bleaching agent may have potentially deleterious effects on general health and specifically dental health., ${ }^{2,79}$

Several studies were conducted to compare the effectiveness of nonprescription OTC bleaching agent, professionally prescribed home bleaching, in-office agent, and DIY product. ${ }^{4,10}$ Studies carried out by Kwon et al and also Mielzareck et al found no significant difference in the enamel surface microhardness after bleaching with Opalescence PF which contains fluoride. ${ }^{4}$ Based on manufacturer disclaimer, addition of fluoride in the Opalescence PF bleaching formulation ensures that enamel microhardness is enhanced and not affected. The study by Kwon et al found no significant difference in enamel microhardness, but Heshmat et al found that the incorporation of remineralizing agent in the bleaching product may enhance enamel microhardness. ${ }^{11}$

A study conducted by Kwon et al also observed no changes in the enamel surface roughness after being subject to professionally prescribed or nonprescription OTC bleaching agent. ${ }^{4}$ In contrast, some other researchers found an increase in the enamel surface roughness after bleaching. ${ }^{12}$ A study by Cavalli et al found a significant increase in the enamel surface roughness after being subjected to a high concentration of bleaching agent.

A clinical study comparing three different bleaching regimes found that bleaching efficacy correlates with the types of bleaching regime, in which in-office bleaching was found to be the most effective with minimal time required to whiten the teeth followed by professionally prescribed home bleaching and nonprescription OTC bleaching. ${ }^{13}$ Subjective assessment of color changes of the teeth VITA shade guide was used in this study

This study was performed to make sense of the confusing findings pertaining to the effectiveness and safety of nonprescription OTC bleaching compared with the professionally prescribed home bleaching. The purpose of this study was to evaluate the efficacy and safety of the professionally prescribed home bleaching and the nonprescription OTC bleaching agents on the color changes, microhardness, surface roughness, and the surface morphology of the human natural tooth, with the null hypothesis that there were no significant differences between the two bleaching procedures.

\section{Materials and Methods}

The conduct of this study fully conformed to the local practices, laws, and regulations. Ethical clearance was obtained from the institutional Human Research Ethic Committee, with the study protocol code JEPeM/15020047. Sample size calculation was carried out using PS software version 3.1.2 (Dupont and Plummer, 1998), with Type 1 error probability $(\alpha)$ of 0.05 and power of the study set at 80 for all parameters. For colorimetric evaluation, with mean difference $(\delta)$ of 7.4 and standard deviation $(\boldsymbol{\sigma})$ of $0.8,{ }^{6}$ two samples were required. For surface roughness, with mean difference $(\delta)$ of $0.08 \mathrm{Ra}$ and standard deviation $(\boldsymbol{\sigma})$ of $0.05 \mathrm{Ra},{ }^{14}$ seven samples were needed, whereas for surface hardness, with mean difference $(\delta)$ of $19 \mathrm{VHN}$ and standard deviation of $29 \mathrm{VHN},{ }^{10} 11$ samples were needed. The highest sample size was used, and after considering 10 percent damage to the samples, 13 samples were needed for each group, with the total of 65 .

Sixty-five intact, extracted human permanent maxillary central incisors were then collected and screened for surface cracks, caries, and fracture under magnification. The roots were then cut $1 \mathrm{~mm}$ below the cemento-enamel junction using hard tissue cutter (Exakt Apparatebau; 22851 Norderstedt, Germany). The buccal surface of the crown was cleaned with pumice and then flattened using a model trimmer (MAESTRA; 48150 Sondika Bilbao, Spain) to obtain an even surface of $14 \times 8 \mathrm{~mm}( \pm 1 \mathrm{~mm})$. The coronal tooth structure was embedded in self-cured acrylic resin (Vertex, The Netherlands) with the flat surface facing the mold base. The exposed surface was polished using sandpaper (WS-FLEX 18, HERMES) with straight handpiece set at the same speed in increasing grit of 250,500 , and $2400 \mu \mathrm{m}$.

The exposed enamel surface of all samples was etched with $35 \%$ phosphoric acid gel for 30 seconds and 15 seconds, respectively, and then stained with red wine (Chateau Du'Pond, Merlot 2008) in test tube for 14 days. The enamel samples were stored in humid environment for 7 days. $^{15}$

Baseline colorimetric measurements were carries out on all 65 samples using Vita Easy Shade Advance 4.0 (VITA Zahnfabrik; H. Rauter GmbH \& Co.KG, Germany). The samples were placed on a white paper to avoid disturbance in spectrophotometer reading from the surrounding. The probe tip was placed in the center perpendicular and in contact with the tooth surface. Then, the displayed results were recorded. The measurement recorded $L^{*}, a^{*}, b^{*}$, where $L^{*}$ stands for luminosity dimensions or whiteness, ranging from 0 (pure black) to 100 (reference white), $a^{*}$ for green-red contrast $\left(-a^{*}=\right.$ green and $+a^{*}=$ red $)$, and $b^{*}$ for blue-yellow contrast $\left(-b^{*}=\right.$ blue and $+b^{*}=$ yellow $)$. Color change $(\Delta \mathrm{E})$ was calculated using formula: $\Delta \mathrm{E}=\left[\left(\Delta \mathrm{L}^{*}\right) 2+\left(\Delta \mathrm{a}^{*}\right) 2+\left(\Delta \mathrm{b}^{*}\right) 2\right] 1 / 2$. Positive $\Delta \mathrm{L}^{*}$ means the samples became whiter, while negative $\Delta \mathrm{L}^{*}$ means samples became darker. ${ }^{14,15}$ The measurement was taken three times for each sample.

Baseline surface hardness measurement was conducted using microhardness tester (Vickers Hardness Tester, VM-50, Fuel Instrument \& Engineers Pvt. Ltd. Kolhapur, Maharashtra 
State, INDIA) for Vickers Hardness Number (VHN) with the use of sets of $100 \mathrm{~g}$ load and 20 seconds dwell time at room temperature $\left(26^{\circ} \mathrm{C}\right)$. Three indentations on the top surface, not closer than $1 \mathrm{~mm}$ to the adjacent indentations or margin of the specimens, were made. The diamond indentation was read on the viewer and VHN was calculated.

Baseline surface roughness of all samples were measured using Profilometer Surf-Corder SE 1200 (Kosaka Laboratory Ltd., Tokyo, Japan) with measuring range of $520 \mu \mathrm{m}$ vertically, $25 \mathrm{~mm}$ horizontally, vertical resolution of $0.008 \mu \mathrm{m}$, and measuring speed of 0.2 and $0.5 \mathrm{~mm} / \mathrm{s}$. Three different areas were selected on the tooth specimen randomly and measurements in different directions were recorded to evaluate the surface roughness value $(\mathrm{Ra})$.

A pH meter (Hanna Instrument, $\mathrm{pH} 210$ Microprocessor $\mathrm{pH}$ meter) was calibrated with the buffered potassium chloride

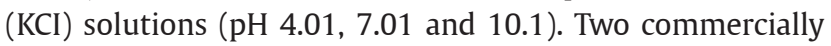
and professionally prescribed (PB) bleaching agents, Opalescence PF 15 Ultradent Product Inc., South Jordan, Utah, USA) and VOCO Perfect Bleach, and two commercial, nonprescription OTC bleaching products, Whitelight Tooth Whitening Set and Crest 3D White ( $\mathbf{- T a b l e ~ 1 )}$ ), were placed in test tubes. The $\mathrm{pH}$ electrode was then immersed in each bleaching gel to allow uniform contact with the electrode tip for 20 minutes at room temperature $\left(24^{\circ} \mathrm{C}\right)$ for $\mathrm{pH}$ measurement. Calibration and cleaning procedure of the electrode was performed before the $\mathrm{pH}$ measurement of each bleaching agent. ${ }^{16}$

All 65 tooth specimens were then randomly divided into five groups ( $n=13$ ) according to bleaching procedures. For control group, no bleaching agent was applied. For PB Opal group (Opalescence PF 15\%), PB Voco group (VOCO Perfect Bleach 10\% gel), and nonprescription OTC WL group (Whitelight Tooth Whitening Set gel), the bleaching agents were applied on tooth specimens approximately $1 \mathrm{~mm}$ thick for 4 to 6 hours (PB Opal and PB Voco) and kept in humid atmosphere at $37^{\circ} \mathrm{C}$. For nonprescription OTC WL, light activation was carried out using manufacturers' light source for 30 minutes. Thereafter, all bleaching gel was washed using plain water, and each sample was stored in distilled water. In the nonprescription OTC Crest group, the enamel surface of the specimens was covered with the bleaching strip (Crest 3D White Strip) for 30 minutes in humid atmosphere at $37^{\circ} \mathrm{C}$. Then, the strip was removed, and the specimens were then stored in distilled water for 7 hours between treatments. Bleaching procedure for all group of bleaching agents was conducted for 10 days consecutively. Bleaching regime for each group summarized in the -Table 1 .

All specimens were again subjected to colorimetric, microhardness, and surface roughness measurement after bleaching procedure.

Five samples, one from each group were randomly selected, gently air dried, dehydrated with alcohol, and gold coated under vacuum pressure using gold coating machine (LEICA EM SCD005) and then analyzed under scanning electron microscope (SEM; scanning electron microscope, Quanta FEG 459). Forty photomicrographs of serial SEM of

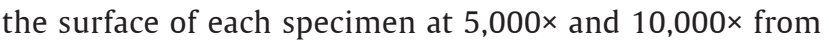
original magnification were obtained. The superficial morphology of enamel was examined and scores were recorded as follows: 0 , enamel with smooth surface morphology; 1 , enamel with slight irregularities; 2 , enamel with moderate irregularities; 3 , enamel with accentuated irregularities with loss of superficial structures. ${ }^{17}$ The photomicrographs of SEM were evaluated in a double-blinded manner by two calibrated examiners. Intra- and inter-examiner agreements were tested using Cohen's Kappa test. ${ }^{18}$

Five samples, one for each group, were selected for atomic force microscopy (AFM) surface topography evaluation. This was done based on mean surface roughness ( $\mathrm{Ra}$ ) obtained from surface roughness evaluation by profilometer. All teeth specimens were analyzed at room temperature in dehydrated state. Images were obtained with a resolution of 512 X 512 pixels per image. Images $100 \mu \mathrm{m} \times 100 \mu \mathrm{m}$ were taken with the AFM software Nanoscope IIIA (Software version 5.12r3, Veeco - Digital Instruments, Santa Barbara, CA) for each specimen. To quantify microroughness, the following methodology was adopted: first, conventional statistical roughness parameters, including Ra that is the arithmetic mean deviation of the surface; RMS that is the root-meansquare deviation of the surface; and $\mathrm{Z}$ range that defines the height between the highest peak and the deepest valley was determined. ${ }^{19,20}$

\section{Statistical Analysis}

Data collected were analyzed using SPSS version 22.0. Color changes, microhardness, and surface roughness pre and postbleaching were analyzed using paired $t$-test. Analysis of variance for repeated measurements (two-way ANOVA) was used to compare the color changes $(\Delta \mathrm{E})$, surface microhardness,

Table 1 Composition, $\mathrm{pH}$, and manufacturer regime of the bleaching protocols

\begin{tabular}{|l|l|l|l|}
\hline Groups & Concentration and $\mathrm{pH}$ & $\mathrm{pH}$ & Application regimen \\
\hline Control & & 7 & Immersed in distilled water \\
\hline PB Opal & $15 \%$ CP & 6.38 & 10 days application, 4-6 hours daily \\
\hline PB Voco & $16 \%$ CP & 5.95 & 10 days application, 4-6 hours daily \\
\hline OTC Crest & Not declared by manufacturer & 4.60 & 10 days application, 30 minutes daily \\
\hline OTC WL & Not declared by manufacturer & 5.97 & $\begin{array}{l}10 \text { days application, 30 minutes with application of } \\
\text { light activator }\end{array}$ \\
\hline
\end{tabular}

Abbreviations: OTC Crest, Crest 3D whitestrip; OTC WL, Whitelight tooth whitening set; PB Opal, Opalescence PF 15\%; PB Voco, Voco perfect bleach 10\%. 
and surface roughness (Ra) between five groups. Mean value was statistically analyzed by one-way analysis of variance (ANOVA) and Turkey's test at the $5 \%$ level of significance. ${ }^{18,21}$ The $p$-value set as significant at $p<0.05$.

\section{Results}

Paired $t$-test revealed that there were significant changes in the $\mathrm{L}^{*}, \mathrm{a}^{*}$ values postbleaching in both control and all bleaching groups. Significant changes of the $b^{*}$ values were only observed in the PB Voco and OTC Crest groups (-Table 2). One-way ANOVA test showed that there was a significant difference in the color changes when the comparison was made between groups with $p<0.001$. Further posthoc Tukey analysis revealed that there were significant differences between all groups except for PB Opal and PB Voco, and PB Opal and OTC Crest with $p=0.682$ and 0.052 , respectively (-Table 3). PB Voco was the most efficient in bleaching the teeth, followed by PB Opal, OTC Crest, and OTC WL.

Paired $t$-test showed that there was a significant increase in the microhardness of enamel surface postbleaching only in PB Opal group with $p<0.001$ ( - Table 4). However, one-way
ANOVA test showed no significant difference in the microhardness changes pre and postbleaching between groups ( $p=0.076)$

Paired $t$-test showed significant increase in the surface roughness of the enamel postbleaching in all test groups with $p<0.001$, respectively (-Table 5). One-way ANOVA test showed significant difference in the surface roughness changes after bleaching procedure between groups with $p<0.001$. Further analysis with posthoc Tukey test revealed that there were significant differences between all groups except PB Opal and PB Voco, and PB Opal and OTC WL groups (- Table 6). The highest mean in the differences of the surface roughness was observed in OTC Crest 3D group followed by OTC WL, PB Opal, and PB Voco groups. These results were further supported by SEM photomicrographs illustrated in - Fig. 1 .

-Fig. 2 shows distribution of enamel surface morphology scores for each group under SEM investigation. The agreement achieved, $K=0.6125$, indicated substantial agreement among the examiners. ${ }^{18}$ Control group exhibits $50 \%$ smooth surface morphology mixed with slight and moderate surface irregularities. Both PB Opal and PB Voco group showed more than $75 \%$ slight irregularities. However, accentuated surface irregularities have been observed in PB Voco

Table 2 Comparison of mean (SD) between pre- and postbleaching colorimetric assessment $\mathrm{L}^{*}$, $\mathrm{a}^{*}$ and $\mathrm{b}^{*}$ values of enamel for all groups

\begin{tabular}{|c|c|c|c|c|c|c|c|}
\hline Groups & $\mathrm{n}$ & Variables & $\begin{array}{l}\text { Prebleaching } \\
\text { mean (SD) }\end{array}$ & $\begin{array}{l}\text { Postbleaching } \\
\text { mean (SD) }\end{array}$ & $\begin{array}{l}\text { Mean difference } \\
(95 \% \mathrm{Cl})\end{array}$ & $T$ statistics (df) & $p$-Value \\
\hline \multirow[t]{3}{*}{ Control } & \multirow[t]{3}{*}{13} & $\mathrm{~L}$ & $37.32( \pm 17.803)$ & $\begin{array}{l}34.26( \pm \\
16.542)\end{array}$ & $3.05(0.096,6.011)$ & $2.250(12)$ & $0.044^{*}$ \\
\hline & & $\mathrm{a}$ & $14.69( \pm 2.754)$ & $8.55( \pm 3.109)$ & $6.15(3.100,9.192)$ & $4.396(12)$ & $0.001^{*}$ \\
\hline & & $\mathrm{b}$ & $17.79( \pm 5.399)$ & $15.58( \pm 5.566)$ & $2.22(-0.522,4.953)$ & $1.763(12)$ & 0.103 \\
\hline \multirow[t]{3}{*}{ (PB Opal) } & \multirow[t]{3}{*}{13} & $\mathrm{~L}$ & $43.05( \pm 13.907)$ & $82.42( \pm 8.418)$ & $\begin{array}{l}-39.36(-47.673 \\
-31.050)\end{array}$ & $-10.319(12)$ & $<0.001^{*}$ \\
\hline & & $\mathrm{a}$ & $15.25( \pm 2.824)$ & $-0.01( \pm 1.405)$ & $\begin{array}{l}15.25(13.331 \\
17.177)\end{array}$ & $17.283(12)$ & $<0.001^{*}$ \\
\hline & & $\mathrm{b}$ & $22.88( \pm 6.699)$ & $21.55( \pm 4.339)$ & $1.34(-2.064,4.741)$ & $0.857(12)$ & 0.408 \\
\hline \multirow[t]{3}{*}{ PB Voco } & \multirow[t]{3}{*}{13} & $\mathrm{~L}$ & $37.00( \pm 9.862)$ & $77.82( \pm 6.654)$ & $\begin{array}{l}-40.82(-47.747 \\
-33.899)\end{array}$ & $-12.847(12)$ & $<0.001^{*}$ \\
\hline & & $\mathrm{a}$ & $16.37( \pm 1.677)$ & $1.76( \pm 1.652)$ & $\begin{array}{l}14.61(13.051, \\
16.165)\end{array}$ & $20.443(12)$ & $<0.001^{*}$ \\
\hline & & $\mathrm{b}$ & $21.32( \pm 6.904)$ & $26.26( \pm 5.493)$ & $\begin{array}{l}-4.94(-9.200 \\
-0.676)\end{array}$ & $-2.525(12)$ & $0.027^{*}$ \\
\hline \multirow[t]{3}{*}{ OTC Crest } & \multirow[t]{3}{*}{13} & $\mathrm{~L}$ & $36.24( \pm 9.800)$ & $66.99( \pm 7.615)$ & $\begin{array}{l}-30.75(-36.029 \\
-25.479)\end{array}$ & $-12.703(12)$ & $<0.001^{*}$ \\
\hline & & $\mathrm{a}$ & $16.62( \pm 2.655)$ & $2.23( \pm 1.453)$ & $\begin{array}{l}13.38(11.831, \\
14.938)\end{array}$ & $18.769(12)$ & $<0.001^{*}$ \\
\hline & & $\mathrm{b}$ & $19.04( \pm 6.103)$ & $24.17( \pm 3.575)$ & $\begin{array}{l}-5.13(-10.084 \\
-0.178)\end{array}$ & $-2.257(12)$ & $0.043^{*}$ \\
\hline \multirow[t]{3}{*}{ OTC WL } & \multirow[t]{3}{*}{13} & L & $39.19( \pm 14.106)$ & $51.48( \pm 7.743)$ & $\begin{array}{l}-12.29(-21.526 \\
-3.058)\end{array}$ & $-2.900(12)$ & $0.013^{*}$ \\
\hline & & $\mathrm{a}$ & $14.83( \pm 4.241)$ & $6.90( \pm 2.941)$ & $7.93(5.028,10.833)$ & $5.954(12)$ & $<0.001^{*}$ \\
\hline & & $\mathrm{b}$ & $18.93( \pm 5.762)$ & $22.95( \pm 4.497)$ & $\begin{array}{l}-4.02(-8.106 \\
0.060)\end{array}$ & $-2.147(12)$ & 0.053 \\
\hline
\end{tabular}

Abbreviations: OTC Crest, Crest 3D whitestrip; OTC WL, Whitelight tooth whitening set; PB Opal, Opalescence PF 15\%; PB Voco, Voco perfect bleach 10\%. Paired $t$-test.

${ }^{*}$ Significant at $p<0.05$. 
Table 3 Comparison of mean $(S D)$ color changes $(\triangle E)$ postbleaching between different groups

\begin{tabular}{|c|c|c|c|c|c|}
\hline Groups & $n$ & $\begin{array}{l}\Delta \mathrm{E} \\
\text { Mean (SD) }\end{array}$ & MS & F statistics (df) & $p$-Value \\
\hline Control & 13 & $9.80( \pm 4.706)$ & \multirow[t]{5}{*}{2880.618} & \multirow[t]{5}{*}{$29.83(4)$} & \multirow[t]{5}{*}{$<0.001^{*}$} \\
\hline PB Opal & 13 & $42.73( \pm 13.629)$ & & & \\
\hline PB Voco & 13 & $44.32( \pm 11.101)$ & & & \\
\hline OTC Crest & 13 & $35.09( \pm 7.957)$ & & & \\
\hline OTC WL & 13 & $20.68( \pm 9.404)$ & & & \\
\hline
\end{tabular}

Abbreviations: OTC Crest, Crest 3D whitestrip; OTC WL, Whitelight tooth whitening set; PB Opal, Opalescence PF 15\%; PB Voco, Voco perfect bleach $10 \%$.

*One-way ANOVA test $<$ significant at $p<0.05$. Posthoc Tukey test: multiple comparisons show significant differences between control and all test groups: PB Voco and OTC Crest ( $p=0.020)$; PB Opal and OTC WL; PB Voco and OTC WL; OTC Crest and OTC WL with $p<0.001$, respectively.

Table 4 Comparison of mean (SD) enamel microhardness (VHN) pre and post bleaching for all groups

\begin{tabular}{|l|l|l|l|l|l|l|}
\hline Groups & $\mathrm{N}$ & $\begin{array}{l}\text { Prebleaching } \\
\text { mean (SD) (VHN) }\end{array}$ & $\begin{array}{l}\text { Postbleaching } \\
\text { mean (SD) (VHN) }\end{array}$ & Mean difference (95\% Cl) & $\begin{array}{l}t \text { statistics } \\
(\mathrm{df})\end{array}$ & $\boldsymbol{p}$-Value \\
\hline Control & 13 & $207.97( \pm 54.915)$ & $240.74( \pm 73.235)$ & $-32.77(-75.013,9.473)$ & $-1.690(12)$ & 0.117 \\
\hline PB Opal & 13 & $191.46( \pm 22.750)$ & $283.90( \pm 68.764)$ & $-92.44(-133.944,-50.928)$ & $-4.852(12)$ & $<\mathbf{0 . 0 0 1 *}$ \\
\hline PB Voco & 13 & $221.28( \pm 57.936)$ & $274.49( \pm 63.142)$ & $-53.21(-109.335,2.925)$ & $-2.065(12)$ & 0.061 \\
\hline OTC Crest & 13 & $230.46( \pm 43.639)$ & $241.59( \pm 42.151)$ & $-11.13(-43.465,21.211)$ & $-0.750(12)$ & 0.468 \\
\hline OTC WL & 13 & $234.28( \pm 48.149)$ & $224.41( \pm 50.392)$ & $9.87(-25.106,44.850)$ & $0.615(12)$ & 0.550 \\
\hline
\end{tabular}

Abbreviations: OTC Crest, Crest 3D whitestrip; OTC WL, Whitelight tooth whitening set; PB Opal, Opalescence PF 15\%; PB Voco, Voco perfect bleach 10\%. $t$ test.

*Significant at $p<0.05$.

Comparison of mean (SD) microhardness changes (Ra) postbleaching between different groups

\begin{tabular}{|c|c|c|c|c|c|}
\hline Groups & $n$ & $\begin{array}{l}\text { Differences } \\
\text { mean (SD) (Ra) }\end{array}$ & MS & F statistics (df) & $p$-Value \\
\hline Control & 13 & $54.10( \pm 53.654)$ & \multirow[t]{5}{*}{6362.052} & \multirow[t]{5}{*}{$2.232(4)$} & \multirow[t]{5}{*}{0.076} \\
\hline PB Opal & 13 & $92.69( \pm 68.316)$ & & & \\
\hline PB Voco & 13 & $81.00( \pm 67.724)$ & & & \\
\hline OTC Crest & 13 & $43.23( \pm 31.192)$ & & & \\
\hline OTC WL & 13 & $46.18( \pm 33.848)$ & & & \\
\hline
\end{tabular}

Abbreviations: OTC Crest, Crest 3D whitestrip; OTC WL, Whitelight tooth whitening set; PB Opal, Opalescence PF 15\%; PB Voco, Voco perfect bleach 10\%. One-way ANOVA.

Table 5 Comparison of mean (SD) enamel surface roughness (Ra) pre and postbleaching for all groups

\begin{tabular}{|c|c|c|c|c|c|c|}
\hline Groups & $n$ & $\begin{array}{l}\text { Prebleaching } \\
\text { mean (SD) (Ra) }\end{array}$ & $\begin{array}{l}\text { Postbleaching } \\
\text { mean (SD) (Ra) }\end{array}$ & Mean difference $(95 \% \mathrm{CI})$ & $t$-statistics (df) & $p$-Value \\
\hline Control & 13 & $0.15( \pm 0.075)$ & $0.19( \pm 0.057)$ & $-0.05(-0.106,0.011)$ & $-1.765(12)$ & 0.103 \\
\hline PB Opal & 13 & $0.09( \pm 0.054)$ & $0.34( \pm 0.181)$ & $-0.25(-0.345,-0.150)$ & $-5.536(12)$ & $<0.001^{*}$ \\
\hline PB Voco & 13 & $0.10( \pm 0.039)$ & $0.34( \pm 0.124)$ & $-0.24(-0.319,-0.157)$ & $-6.374(12)$ & $<0.001^{*}$ \\
\hline OTC Crest & 13 & $0.06( \pm 0.012)$ & $0.54( \pm 0.118)$ & $-0.48(-0.549,-0.412)$ & $-15.219(12)$ & $<0.001^{*}$ \\
\hline OTC WL & 13 & $0.07( \pm 0.023)$ & $0.42( \pm 0.155)$ & $-0.35(-0.443,-0.252)$ & $-7.922(12)$ & $<0.001^{*}$ \\
\hline
\end{tabular}

Abbreviations: OTC Crest, Crest 3D whitestrip; OTC WL, Whitelight tooth whitening set; PB Opal, Opalescence PF 15\%; PB Voco, Voco perfect bleach 10\%. Paired $t$-test.

* Significant at $p<0.05$.

which is absent in the PB Opal group. OTC Crest group contains more than 50\% accentuated enamel surface irregularities mixed with moderate alterations. In the OTC WL group, enamel surface was mostly represented with moderate alterations with small percentage of slight and accentuated surface irregularities. 
Table 6 Comparison of mean (SD) surface roughness changes (Ra) postbleaching between groups

\begin{tabular}{|c|c|c|c|c|c|}
\hline Groups & $n$ & $\begin{array}{l}\text { Differences } \\
\text { mean (SD) (Ra) }\end{array}$ & MS & F statistics (df) & $p$-Value \\
\hline Control & 13 & $0.09( \pm 0.061)$ & \multirow[t]{5}{*}{0.278} & \multirow[t]{5}{*}{$16.302(4)$} & \multirow[t]{5}{*}{$<0.001^{*}$} \\
\hline PB Opal & 13 & $0.25( \pm 0.161)$ & & & \\
\hline PB Voco & 13 & $0.24( \pm 0.135)$ & & & \\
\hline OTC Crest & 13 & $0.48( \pm 0.114)$ & & & \\
\hline OTC WL & 13 & $0.35( \pm 0.156)$ & & & \\
\hline
\end{tabular}

Abbreviations: OTC Crest, Crest 3D whitestrip; OTC WL, Whitelight tooth whitening set; PB Opal, Opalescence PF 15\%; PB Voco, Voco perfect bleach $10 \%$.

* One-way ANOVA test < significant at $p<0.05$. Posthoc Tukey test: multiple comparisons show significant differences between control and PB Opal $(p=0.003)$; control and PB Voco $(p=0.004)$; control and OTC Crest and OTC WL with $p<0.001$, respectively; PB Opal and OTC Crest, PB Voco and OTC Crest with $p<0.001$, respectively; PB Voco and OTC WL $(p=0.034)$; OTC Crest and OTC WL $(p=0.013)$.

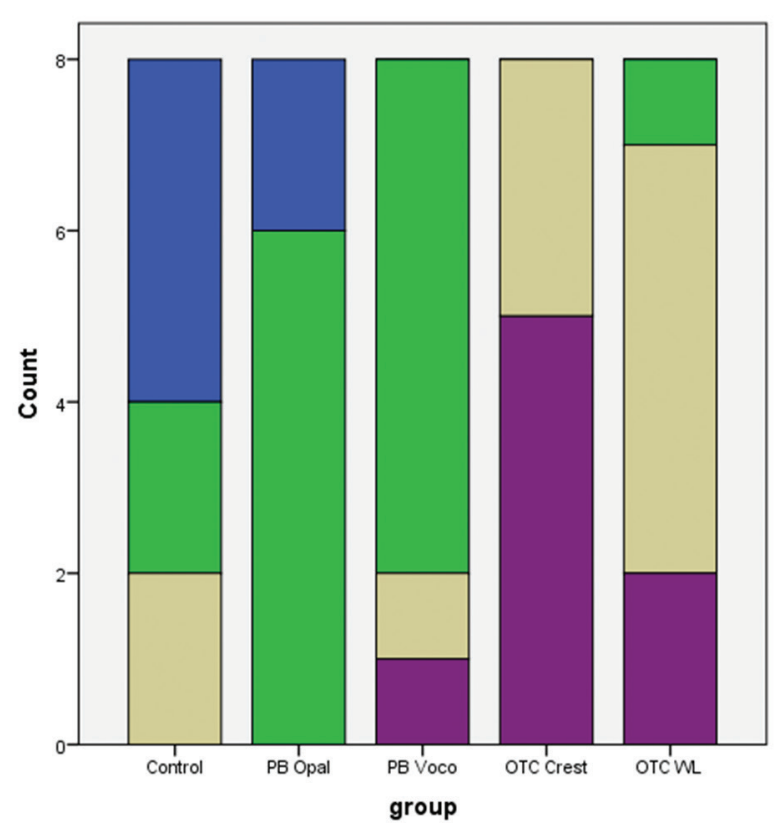

Fig. 1 Distribution of enamel surface morphology scores for each group $(n=65)$.

-Fig. 1 shows photomicrographs SEM at 5000x magnifications of control group $(A)$, which demonstrates intact enamel with smooth surface morphology, while PB Voco (B and C) show enamel with slight irregularities. Group OTC Crest (D) show enamel with accentuated irregularities, increased in large and deep dimension of porosities with appearance of acid etch enamel, while OTC WL (E) show enamel with moderate irregularities with increased porosities and sign of depressions and erosions.

-Fig. 3 shows AFM photomicrographs of all groups at $100 \mu \mathrm{m}$. Enamel surface topography in all groups showed various ranges of irregularities. Enamel topography in $\mathrm{PB}$ Opal and PB Voco were comparable to the control group with less number of grooves and pits and smoother grooves and less depth. In OTC crest and OTC WL, enamel surface showed moderate to severe alteration with increase in roughness. Over the counter Crest enamel surface topography show shallow pits and grooves in the center but deeper and wider grooves in the periphery of the enamel surface. OTC WL group demonstrate presence of deep and wide groove in the center of the enamel surface with numerous small and shallow pits and grooves.

\section{Discussion}

In this study, colorimetric measurement analysis showed that $\mathrm{L}^{*}$ values, which represent the brightness, increased significantly in all test groups postbleaching. The $\mathrm{a}^{*}$ values, which represent the green-red contrast, decreased significantly in all test groups postbleaching. This suggests that regardless of the bleaching regime or concentration of the bleaching agents, this study exhibits efficacy of tooth whitening, as was also found in several studies. ${ }^{6,8,10}$ From the results, PB Voco showed similar bleaching efficacy with PB Opal, while PB Opal has the same bleaching efficacy with OTC Crest. Karadas and Duymus in 2015 also concluded that bleaching with strip-type or gel-type OTC products have the same efficacy in whitening the tooth compared with Opalescence PF $10 \%{ }^{8}$ In this study, it was found that there was a significant decrease in the $\mathrm{L}^{*}$ values of the control group whose samples were not bleached, but only stored in distilled water. This suggests that the teeth stored in distilled water continued to become discolored or darkened over time. Whereas, in the other groups, the significant color changes were such that there was an increase of $\mathrm{L}^{*}$ value, which means the teeth became whiter.

Despite having the same efficacy with professionally prescribed bleaching agent, there is no long-term evidence of safety and bleaching stability with the nonprescription OTC products. The OTC products may give immediate effects to the color changes; however, it would be mandatory to monitor the long-term results and their detrimental effects on the enamel. The nonprescription OTC products active components' concentrations have not been declared by the manufacturer. Thus, concentration-related efficacy of different bleaching agents could not be concluded in this study.

Surface microhardness alteration is said to be associated with the loss and gain of minerals (balance in remineralization and demineralization) of the dental hard tissues ${ }^{21,22}$ which is linearly associated with mineral content. ${ }^{23}$ This study reveals significant increase in the enamel microhardness in the PB Opal group compared with the other groups. Normal value of human enamel microhardness was recorded as being in the range of 211.2 to $443.07(\mathrm{HVN}) .{ }^{24}$ In this study, 

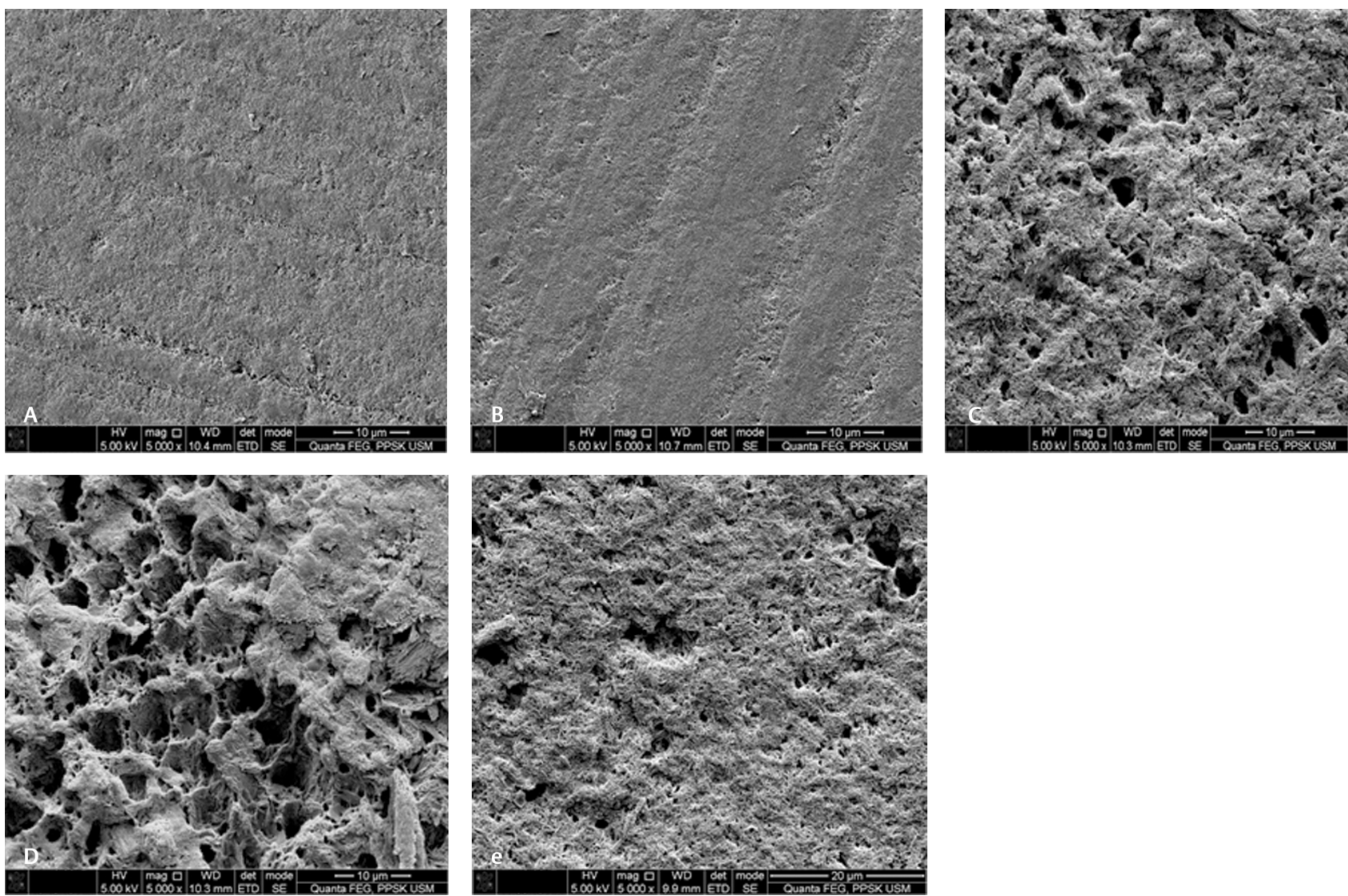

Fig. 2 (A) Scanning electron microscope photomicrograph of control group demonstrates intact enamel with smooth surface morphology. (B) Scanning electron microscope photomicrograph of PB Opal Group demonstrates enamel with slight irregularities. (C) Scanning electron microscope photomicrograph of PB Voco Group demonstrates enamel with slight irregularities. (D) Scanning electron microscope photomicrograph of OTC Crest Group showed enamel with accentuated irregularities, and increase in large and deep dimension of porosities with appearance of acid etch enamel. (E) Scanning electron microscope photomicrograph of OTC WL Group showed enamel with moderate irregularities with increased porosities and sign of depressions and erosions.

initial prebleaching enamel microhardness was found to be in the normal range except in the PB Opal group and control group. However, the result postbleaching showed significant increase in the enamel surface microhardness in the PB Opal group. This could be due to the fluoride incorporation in the bleaching agent ${ }^{1}$ which causes less demineralization in the enamel surface. ${ }^{25}$ PB Opal group contains PF (potassium nitrate and fluoride). The 0.11 percent ion fluoride in the opalescence PF formulation causes less hazardous effects on the enamel mineral content. ${ }^{26}$

Storage media used in this study was normal saline instead of normal or artificial saliva which has been found to provide protection and recovery to bleached enamel. ${ }^{27,28}$ This not only eliminates the possible confounding factor of potential remineralization effect form saliva in the bleached enamel but also further strengthens the beneficial effect of fluoride addition in PB Opal. ${ }^{127-29}$ The relevance of maintaining enamel surface hardness to the normal value after bleaching is to ensure the integrity of the outermost layer of the teeth is healthy, thus serving its main function in the oral cavity.

Interaction of the bleaching agent and the oral tissue is critically important as the usage of the bleaching agent may negatively affect the oral structure. ${ }^{30}$ Altered enamel surface roughness has become a major problem in vital bleaching. A few researchers have found that there are increases in the enamel surface roughness after the bleaching procedure. ${ }^{4,12,21,30-32}$ This is due to the oxidizing process that occurs during bleaching treatment. ${ }^{21}$ In this study, the profilometer readings showed significant increase in the enamel surface roughness in all experimental groups. This is in contrast with other studies which reported no changes in the enamel surface roughness after bleaching. ${ }^{32-34}$ In this study, the surface roughness was seen when the enamel was bleached with the lower concentration of active agent, whereas Pinto and colleagues and Cavalli and colleagues found only significant increase in the enamel surface roughness with higher concentration carbamide peroxide or hydrogen peroxide. The increased enamel surface roughness postbleaching may be due to the low $\mathrm{pH}$ of the bleaching solutions. $\mathrm{PH}$ value contributes as an important factor in the reactions of the bleaching process; however, this low-pH bleaching solution leads to demineralization changes with erosion pattern, which is believed to occur irreversibly. ${ }^{35,36}$ In this present study, OTC bleaching products give lower $\mathrm{pH}$ measurement ( $\boldsymbol{\sim}$ Table $\mathbf{1}$ ) than the professionally prescribed bleaching agents which further leads to the erosive effect on enamel surface. ${ }^{4,37}$ This validates the result of the highest surface roughness seen in group bleached with nonprescription OTC products 


\section{Atomic Force Microscopy}

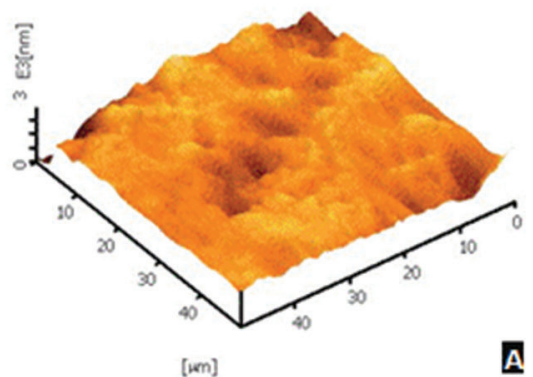

A

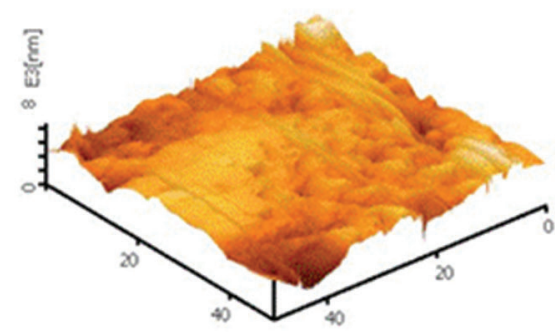

[um]

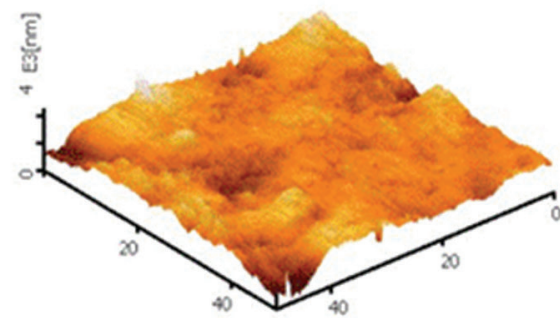

$[\mathrm{mm}]$

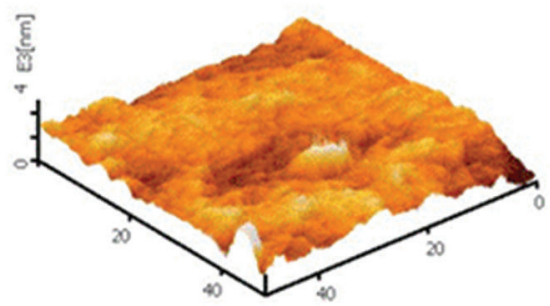

$[\mathrm{m}]$

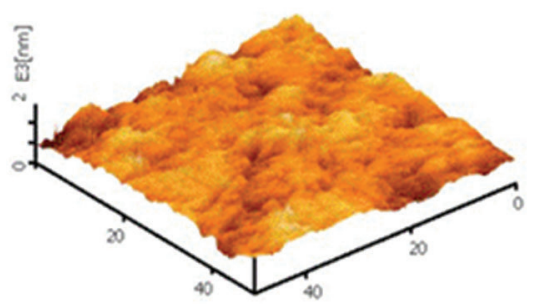

[um]

C

D

E

Fig. 3 (A) Atomic force microscopy photomicrographs of control group at $100 \mu \mathrm{m}$. (B) Atomic force microscopy photomicrographs of PB Opal group at $100 \mu \mathrm{m}$. (C) Atomic force microscopy photomicrographs of PB Voco group at $100 \mu \mathrm{m}$. (D) Atomic force microscopy photomicrographs of OTC Crest group at $100 \mu \mathrm{m}$. (E) Atomic Force Microscopy Photomicrographs of OTC WL group at $100 \mu \mathrm{m}$.

(OTC Crest and OTC WL) compared with professionally prescribed bleaching agent. Increase in the enamel surface roughness of bleached enamel is a concern as rough enamel surface was found to attract more adherence of Streptococcus mutans (S. mutans) compared with unbleached surface. ${ }^{38,39}$ Adhesion of $S$. mutans to the bleached enamel surface acts as an important contribution to the initiation and progression of dental caries and periodontal disease. ${ }^{39}$

The profilometer readings of this study are supported by the SEM and AFM data. SEM has been widely used for the qualitative evaluation of surface morphology of enamel and dentine following tooth bleaching. Various morphologic changes has been observed in previous studies, characterized by mild interprismatic dissolution, appearance of deep longitudinal cavities at the superficial part of enamel not affecting dentine, dissolution of enamel superficial area with opening of dentinal tubules, intermittent depression of various depths and diameters, dissolution of superficial enamel, and loss or eroded enamel prism core with retained periphery area, apparent cross-striation, and striae of retzius ${ }^{4,40-42}$.

It is known that enamel, when exposed to solutions with lower than $\mathrm{pH}$ 5.5, will begin to dissolve, appearing as demineralization. The $\mathrm{pH}$ of nonprescription OTC Crest bleaching agent in this study was lower than the critical $\mathrm{pH}$ of enamel (pH 4.60). Due to the lowest $\mathrm{pH}$ recorded for non-prescription OTC Crest group, it supported the result of accentuated morphological changes for this bleaching group. The PB Opal group, which had significant increase in surface hardness, showed only mild surface morphology alteration in the SEM result. The increase in enamel surface microhardness reflects the uptake of minerals in the enamel; thus, less enamel surface alteration or demineralization upon observation through SEM.

AFM is capable of scanning objects up to atomic resolution with minimal sample preparation. AFM provides a three-dimensional surface profile with high resolutions. This technique has been widely used to characterize the erosion of enamel and dentine. ${ }^{43}$ In the AFM result, the enamel topography in all groups shows various ranges of irregularities. Nonprescription OTC bleaching groups (OTC Crest and OTC WL) exhibit more numerous deeper peaks and valleys. This is supported by a previous study which suggests a more microporous layer on the enamel tissues. ${ }^{44}$ However, enamel surface topography in PB Opal group showed fewer alterations compared with the other groups in our study. This could possibly be due to the presence of sodium fluoride incorporated in the bleaching agent which leads to remineralizing effects, as found by other researchers. ${ }^{20,45}$

Hydroxyapatite on tooth surface is undergoing a unique interaction with salivary components in the oral environment, which involves the interchange of various ions that regulate the remineralization and demineralization process. ${ }^{36}$ The changes of human enamel after tooth bleaching in experimented in vitro study may not be clinically relevant, as it is difficult to replicate actual oral environment which varies from individual to individual. 


\section{Conclusions}

Within the limitation of this study, it can be concluded that

1. All bleaching agents showed significant color changes with an increase in the brightness and green-red contrast. Professional prescribed bleaching agents were more efficient in whitening teeth compared with the OTC bleaching products

2. PB Opal (Professionally Prescribed Opalescence PF 15\%) showed significant increase in enamel microhardness compared with other bleaching agents used in our study.

3. All groups showed significant increase in enamel surface roughness

4. PB opal showed enamel surface morphology the same as unbleached enamel, while the other groups showed enamel morphological changes ranging from mild to accentuated

5. All groups showed a range of surface topography. Nonprescription OTC groups showed the roughest surface topography, characterized by increase in grooves and porosities.

6. Within the limitations of this present study, it can be concluded that professionally prescribed bleaching agent Opalescence PF $15 \%$ is effective in whitening the tooth with positive outcomes in maintaining enamel surface hardnessin vitro, while the other bleaching products used in this study may be effective but have deleterious effects on the enamel.

\section{Key Messages}

Care needs to be taken when using bleaching agents, especially with regard to nonprescription, OTC bleaching agent, as it can cause significant changes to enamel with repeated usage.

\section{Note}

This study was presented on the Postgraduate Research Day, April 27, 2017, at the School of Dental Sciences, Universiti Sains Malaysia, Health Campus, Universiti Sains Malaysia, 16150 Kota Bharu, Kelantan, Malaysia.

\section{Funding}

This study was funded by the USM Short Term grant no.304/PPSG/61313102.

\section{Conflict of Interest}

None declared.

\section{Acknowledgment}

The authors would like to thank Universiti Sains Malaysia for research grant approval of USM/PPSG/61313102.

\section{References}

1 Chen HP, Chang CH, Liu JK, Chuang SF, Yang JY. Effect of fluoride containing bleaching agents on enamel surface properties. J Dent 2008;36(9):718-725
2 Alqahtani MQ. Tooth-bleaching procedures and their controversial effects: A literature review. Saudi Dent J 2014;26(2):33-46

3 Kwon SR, Wertz PW. Review of the mechanism of tooth whitening. J Esthet Restor Dent 2015;27(5):240-257

4 Kwon SR, Kurti SR, Oyoyo U, Li Y. Effect of various tooth whitening modalities on microhardness, surface roughness and surface morphology of the enamel. Odontology 2015;103(3):274-279

5 Greenwall L, Bleaching Techniques In Restorative Dentistry: An Illustrated Guide. CRC Press; 2001

6 Dietschi D, Rossier S, Krejci I. In vitro colorimetric evaluation of the efficacy of various bleaching methods and products. Quintessence Int 2006;37(7):515-526

7 Haywood VB. History, safety, and effectiveness of current bleaching techniques and applications of the nightguard vital bleaching technique. Quintessence Int 1992;23(7):471-488

8 Karadas M, Duymus ZY. In vitro evaluation of the efficacy of different over-the-counter products on tooth whitening. Braz Dent J 2015;26(4):373-377

9 Li Y, Greenwall L. Safety issues of tooth whitening using peroxide-based materials. Br Dent J 2013;215(1):29-34

10 Mielczarek A, Klukowska M, Ganowicz M, Kwiatkowska A, Kwaśny M. The effect of strip, tray and office peroxide bleaching systems on enamel surfaces in vitro. Dent Mater 2008;24(11):1495-1500

11 Heshmat H, Ganjkar MH, Miri Y, Fard MJK. The effect of two remineralizing agents and natural saliva on bleached enamel hardness. Dent Res J (Isfahan) 2016;13(1):52-57

12 Cavalli V, Arrais CA, Giannini M, Ambrosano GM. High-concentrated carbamide peroxide bleaching agents effects on enamel surface. J Oral Rehabil 2004;31(2):155-159

13 Auschill TM, Hellwig E, Schmidale S, Sculean A, Arweiler NB. Efficacy, side-effects and patients' acceptance of different bleaching techniques (OTC, in-office, at-home) Oper Dent 2005;30(2):156-163

14 Delfino CS, Chinelatti MA, Carrasco-Guerisoli LD, Batista AR, Fröner IC, Palma-Dibb RG. Effectiveness of home bleaching agents in discolored teeth and influence on enamel microhardness. J Appl Oral Sci 2009;17(4):284-288

15 Villalta P, Lu H, Okte Z. Garcia-Godoy F, Powers JM. Effects of staining and bleaching on color change of dental composite resins. J Prosthet Dent 2006;95(2):137-142

16 Dominguez JA, Bittencourt B, Michel M, Sabino N, Gomes JC, Gomes OM. Ultrastructural evaluation of enamel after dental bleaching associated with fluoride. Microsc Res Tech 2012;75(8):1093-1098

17 Ferreira SdS. Araújo JLN, Morhy ON, Tapety CMC, Youssef MN, Sobral MAP. The effect of fluoride therapies on the morphology of bleached human dental enamel. Microsc Res Tech 2011;74:512-516

18 McHugh ML. Interrater reliability: the kappa statistic. Biochem Med (Zagreb) 2012;22(3):276-282

19 Pedreira De Freitas AC, Botta SB, Teixeira FdeS, Salvadori MCBS, Garone-Netto N. Effects of fluoride or nanohydroxiapatite on roughness and gloss of bleached teeth. Microsc Res Tech 2011;74(12):1069-1075

20 Poggio C, Ceci M, Beltrami R, Lombardini M, Colombo M. Atomic force microscopy study of enamel remineralization. Ann Stomatol (Roma) 2014;5(3):98-102

21 Pinto CF, Oliveira Rd, Cavalli V, Giannini M. Peroxide bleaching agent effects on enamel surface microhardness, roughness and morphology. Braz Oral Res 2004;18(4):306-311

22 Mondelli RFL, Gabriel TRCG, Rizzante FAP, Magalhães AC, Bombonatti JFS, Ishikiriama SK. Do different bleaching protocols affect the enamel microhardness? Eur J Dent 2015;9 (1):25-30 
23 White DJ. The application of in vitro models to research on demineralization and remineralization of the teeth. Adv Dent Res 1995;9(3):175-193

24 Ávila AJM, Alonso VZ, Alcocer GM, Castañón GAM, Marín NP, González JR. Analysis of the surface of healthy and fluorotic human enamel using microhardness test. Superf Vacio 2017;30:6-9

25 de Oliveira R, Paes Leme AF, Giannini M. Effect of a carbamide peroxide bleaching gel containing calcium or fluoride on human enamel surface microhardness. Braz Dent J 2005;16(2):103-106

26 Basting RT, Rodrigues AL, Jr, Serra MC. The effects of seven carbamide peroxide bleaching agents on enamel microhardness over time. J Am Dent Assoc 2003;134(10):1335-1342

27 DE Abreu DR, Sasaki RT, Amaral FLB, Flório FM, Basting RT. Effect of home-use and in-office bleaching agents containing hydrogen peroxide associated with amorphous calcium phosphate on enamel microhardness and surface roughness. J Esthet Restor Dent 2011;23(3):158-168

28 Zeczkowski M, Tenuta LMA, Ambrosano GMB, Aguiar FHB, Lima DANL. Effect of different storage conditions on the physical properties of bleached enamel: An in vitro vs. in situ study. J Dent 2015;43(9):1154-1161

29 Attin T, Kielbassa AM, Schwanenberg M, Hellwig E. Effect of fluoride treatment on remineralization of bleached enamel. J Oral Rehabil 1997;24(4):282-286

30 Moraes RR, Marimon JL, Schneider LF. Correr Sobrinho L, Camacho GB, Bueno M. Carbamide peroxide bleaching agents: effects on surface roughness of enamel, composite and porcelain. Clin Oral Investig 2006;10(1):23-28

31 Cavalli V, Giannini M, Carvalho RM. Effect of carbamide peroxide bleaching agents on tensile strength of human enamel. Dent Mater 2004;20(8):733-739

32 Markovic L, Jordan RA, Lakota N, Gaengler P. Micromorphology of enamel surface after vital tooth bleaching. J Endod 2007;33(5):607-610

33 Worschech CC, Rodrigues JA, Martins LRM, Ambrosano GMB. In vitro evaluation of human dental enamel surface roughness bleached with $35 \%$ carbamide peroxide and submitted to abrasive dentifrice brushing. Pesqui Odontol Bras 2003;17(4):342-348
34 Faraoni-Romano JJ, Da Silveira AG, Turssi CP, Serra MC. Bleaching agents with varying concentrations of carbamide and/or hydrogen peroxides: effect on dental microhardness and roughness. J Esthet Restor Dent 2008;20(6):395-402, discussion 403-404

$35 \mathrm{Xu} \mathrm{B}, \mathrm{Li} \mathrm{Q}$ Wang Y. Effects of $\mathrm{pH}$ values of hydrogen peroxide bleaching agents on enamel surface properties. Oper Dent 2011;36(5):554-562

36 Dawes $\mathrm{C}$. What is the critical $\mathrm{pH}$ and why does a tooth dissolve in acid? J Can Dent Assoc 2003;69(11):722-724

37 Azrak B, Callaway A, Kurth P, Willershausen B. Influence of bleaching agents on surface roughness of sound or eroded dental enamel specimens. J Esthet Restor Dent 2010;22(6):391-399

38 Hosoya N, Honda K, lino F, Arai T. Changes in enamel surface roughness and adhesion of Streptococcus mutans to enamel after vital bleaching. J Dent 2003;31(8):543-548

39 Gürgan S, Bolay S, Alaçam R. In vitro adherence of bacteria to bleached or unbleached enamel surfaces. J Oral Rehabil 1997;24(8):624-627

40 Klarić E, Marcius M, Ristić M, Sever I, Prskalo K, Tarle Z. Surface changes of enamel and dentin after two different bleaching procedures. Acta Clin Croat 2013;52(4):419-429

41 Izquierdo-Barba I, Torres-Rodríguez C, Matesanz E, Vallet-Regí M. New approach to determine the morphological and structural changes in the enamel as consequence of dental bleaching. Mater 2015;141:302-306

42 Abouassi T, Wolkewitz M, Hahn P. Effect of carbamide peroxide and hydrogen peroxide on enamel surface: an in vitro study. Clin Oral Investig 2011;15(5):673-680

43 Parker AS, Patel AN, Al Botros R, et al. Measurement of the efficacy of calcium silicate for the protection and repair of dental enamel. J Dent 2014;42(Suppl 1):S21-S29

44 Soares DG, Ribeiro APD, Sacono NT, Loguércio AD, Hebling J, Costa CA. Mineral loss and morphological changes in dental enamel induced by a $16 \%$ carbamide peroxide bleaching gel. Braz Dent J 2013;24(5):517-521

45 Carvalho FGd, Brasil VLM, Silva Filho TJd, Carlo HL, Santos RLd, Lima BASGd.. Protective effect of calcium nanophosphate and CPP-ACP agents on enamel erosion. Braz Oral Res 2013;27:463-470 